\title{
Tiny ruptured coronary aneurysm with coronary-pulmonary arterial fistula
}

\author{
Shunsuke Sakamoto ${ }^{1}$ Shinji Kanemitsu ${ }^{1} \cdot$ Hideto Shimpo $^{1} \cdot$ Tairo Kurita $^{1}$
}

Received: 10 May 2018 / Accepted: 17 August 2018 / Published online: 20 August 2018

(c) The Author(s) 2018

\begin{abstract}
A 44-year-old man was admitted to our hospital with chest pain. We diagnosed him with pericardial effusion collection because of a spontaneous ruptured coronary aneurysm of $1.5 \mathrm{~cm}$ with coronary pulmonary arterial fistula (CPAF) by enhanced computed tomography and angiography. We completely resected the ruptured aneurysm and safely closed the CPAF. Rupture of coronary aneurysms with CPAF is rare, especially tiny aneurysms. In previous reports, most cases were older women and the diameter of the ruptured aneurysms was greater than $3.0 \mathrm{~cm}$. We report a case of a middle-aged man with a tiny ruptured coronary aneurysm with CPAF.
\end{abstract}

Keywords Coronary artery aneurysm $\cdot$ Coronary pulmonary arterial fistula

\section{Introduction}

Coronary pulmonary arterial fistula (CPAF) is a congenital or acquired abnormality of coronary anatomy. CPAF consists of communication between a coronary artery and a pulmonary artery. Although approximately a quarter of all CAPFs may become aneurysmal, spontaneous rupture of the coronary aneurysm with CPAF is relatively rare. We report here a successful surgical case of a tiny ruptured coronary aneurysm with CPAF.

\section{Case report}

A 44-year-old man presented to a previous hospital with severe chest pain. Enhanced computed tomography, which was performed in the emergency department, showed a crescent-shaped low density area in the ascending aorta and mild pericardial effusion. With suspected Stanford A type aortic dissection, the patient was transported to our hospital for therapy. The 4th day after admission, enhanced computed tomography showed a 1.5 -cm-diameter coronary aneurysm

Shunsuke Sakamoto

shunsukes302045@yahoo.co.jp

1 Department of Thoracic and Cardiovascular Surgery, Mie University Graduate School of Medicine, 2-174, Edobashi, Tsu, Mie 514-8507, Japan
(Fig. 1a). Coronary angiography showed a coronary aneurysm with papillary projection and shunt flow from the coronary artery to pulmonary artery. We diagnosed this case as a tiny ruptured coronary aneurysm with CAPF (Fig. 1b).

Owing to the patient's stable condition, he was scheduled for an elective operation. Surgical intervention was performed through median sternotomy with cardiopulmonary bypass. There was sanguineous pericardial effusion and intraoperative epiaortic ultrasonography revealed that the ascending aortic wall was intact. We identified and occluded one afferent vessel of the aneurysm. This vessel was derived from the left main trunk. We then confirmed the aneurysm, which was not contrasted by left coronary angiography. The afferent vessel was closed by suture. We recognized that an efferent vessel of the aneurysm connected with the pulmonary artery trunk in two locations. We closed the two orifices by purse-string suture. The aneurysm with the papillary projection was then removed from the patient (Fig. 2).

The patient's postoperative course was uneventful. Histopathology of the resected aneurysmal wall showed hyalinization and an internal elastic membrane disappeared at the papillary projection (Fig. 3). 
Fig. 1 a Enhanced computed tomography findings. A 1.5-cm-diameter coronary aneurysm (arrow) derived from the left main trunk. b Coronary angiography shows a coronary aneurysm with a papillary projection (arrow) and shunt flow of the coronary artery to pulmonary artery

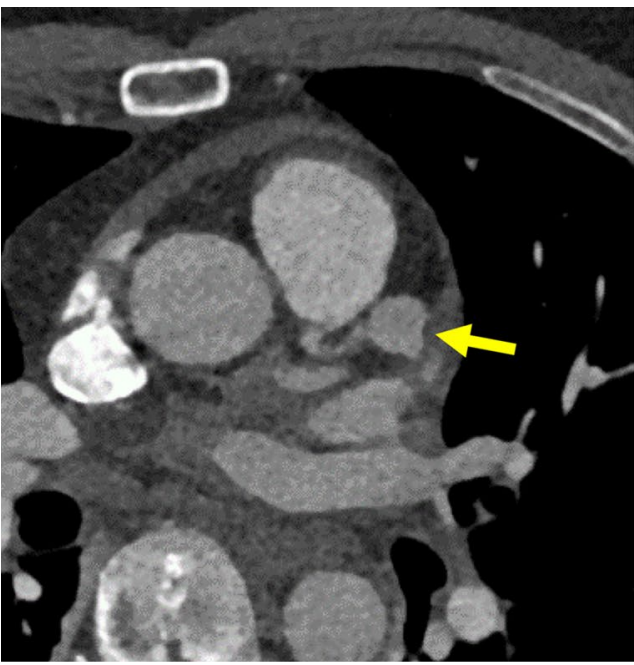

A

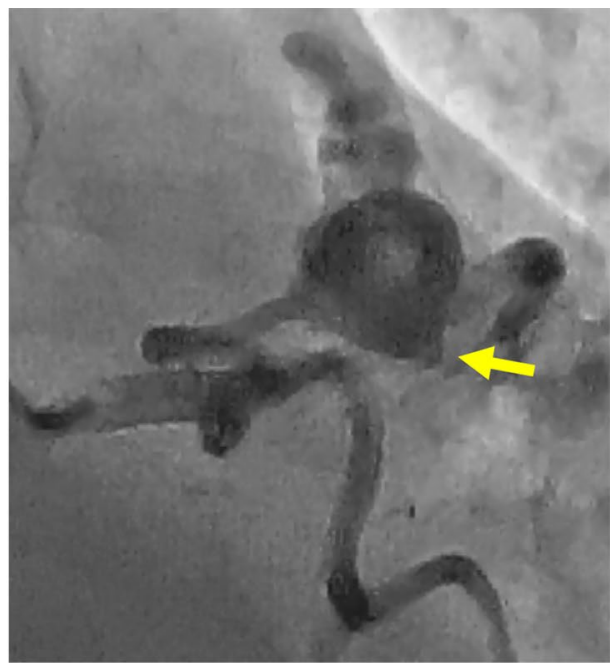

B

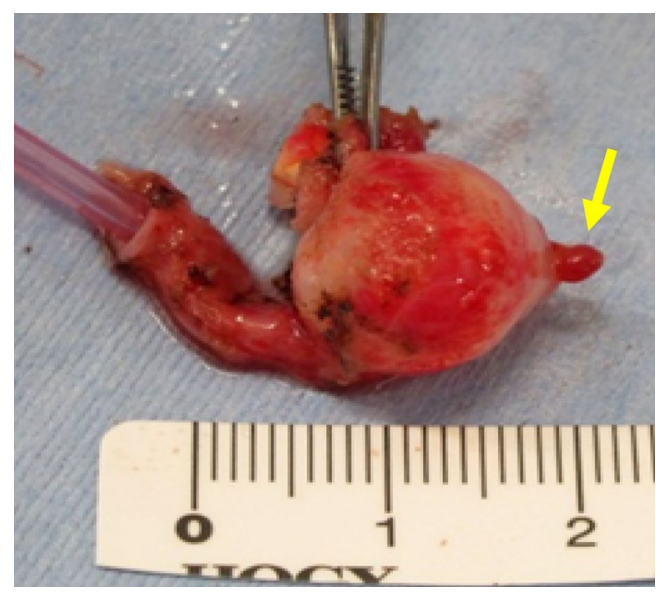

Fig. 2 The aneurysm with a papillary projection (arrow) was surgically removed

\section{Comment}

CPAF is a type of coronary artery fistulas and is an abnormal communication between an epicardial coronary artery and a pulmonary artery. Although 19-26\% of CAPFs may become aneurysmal [1-3], a spontaneous ruptured coronary aneurysm is rare. To the best of our knowledge, there are 24 cases of spontaneous ruptured aneurysm with CPAF, including our case in Japan.

Ishii [4] reviewed 23 cases of a ruptured coronary aneurysm with CPAF. In this review, the average age of the patients was 67.4 year old (range 57-89 years old), and $96 \%$ of the patients were female. The ruptured coronary aneurysm was greater than $3 \mathrm{~cm}$ in diameter, except for only one case. In our case, a 44-year-old man suffered

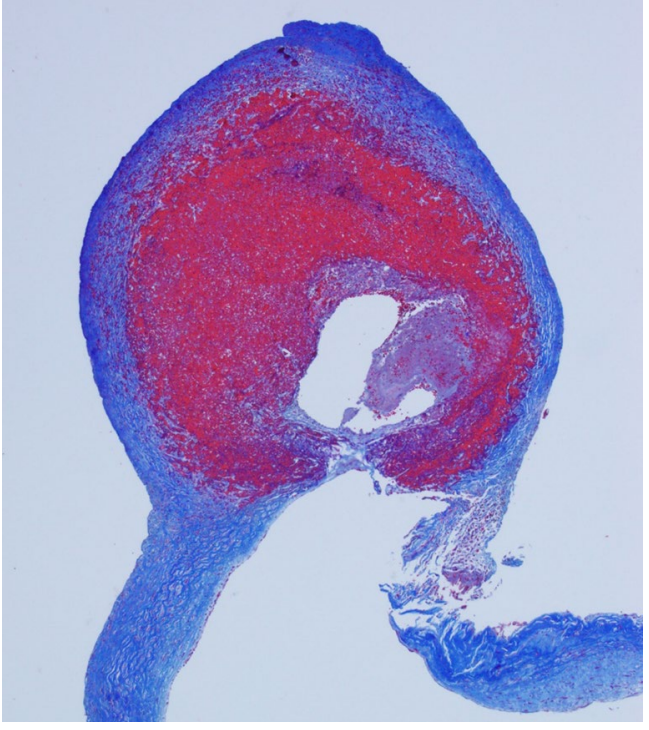

Fig. 3 Histological findings. Masson's trichrome stain $(\times 40)$ shows that the internal elastic membrane has disappeared at the papillary projection

from a tiny ruptured coronary aneurysm with a diameter of $1.5 \mathrm{~cm}$.

The common reasons for coronary aneurysm are atherosclerosis, Kawasaki disease, congenital, trauma, angioplasty, arteritis, infection, connective tissue disorders, and dissection [5]. Our patient did not have any evidence of collagen vascular diseases, chest trauma, or other diseases. Coronary angiography showed no atherosclerosis lesions and all of the vessels were smooth. Therefore, this aneurysm with CPAF may have occurred as a result of high flow of blood from a high-pressure chamber (i.e., aorta) to a low-pressure chamber (i.e., pulmonary artery) due to the fistula. The fistula might have been congenital in origin [6]. 
To permanently close the point of bleeding and CPAF, surgical ligation and percutaneous closure are the currently available options.

Ishii [4] reported that all of the patients who received operations were discharged after surgery. Moreover, 13 of 18 cases $(72 \%)$ were treated on the emergency basis. The optimal management strategy has not been established because of the rarity of a ruptured coronary aneurysm with CPAF. However, surgical treatment should be indicated to prevent rupture of the aneurysm and close the CPAF, even if the size of the aneurysm is small. Most of the ruptured cases involved coronary artery aneurysms $>30 \mathrm{~mm}$ in diameter, but a case of rupture in $10 \mathrm{~mm}$ aneurysm had been reported [7]. Thus, coronary aneurysm with CPFA of any size should be considered a surgical indication. Complete resection of the aneurysm and closure of the CPAF under direct vision during cardiopulmonary bypass provided a safe operation and good outcome in our case. Coronary CT imaging yields beneficial information such as the anatomic location of coronary arteries, the fistula and the aneurysm, it may help to perform the appropriate surgical procedure.

Open Access This article is distributed under the terms of the Creative Commons Attribution 4.0 International License (http://creativeco mmons.org/licenses/by/4.0/), which permits unrestricted use, distribution, and reproduction in any medium, provided you give appropriate credit to the original author(s) and the source, provide a link to the Creative Commons license, and indicate if changes were made.

\section{References}

1. Urrutia-SCO, Falaschi G, Ott DA, et al. Surgical management of 56 patients with congenital coronary artery fistulas. Ann Thorac Surg. 1983;35:300-7.

2. Said SA, el Gama MI. Coronary angiographic morphology of congenital coronary arteriovenous fistulas in adult: report of four new cases. Catheter Carsiovasc Diagn. 1995;35:29-35.

3. Verdini D, Vargas D, Kuo A, et al. Coronary-pulmonary artery fistulas: a systematic review. J Thorac Imaging. 2016;31:380-90.

4. Ishii H, Nakamura K, Nakamura E, et al. A case of ruptured coronary artery aneurysm with coronary artery pulmonary artery fistula and review of 23 cases. Jpn J Cardiovasc Surg. 2016;45:80-3.

5. Syed M, Lesch M. Coronary artery aneurysm: a review. Prog Cardiovasc Dis. 1997;40:77-84.

6. Saxena P, Konstantinov IE, Burstow D, et al. Surgical repair of a large coronary artery aneurysm with arteriovenous fistula. J Thorac Cardiovasc Surg. 2006;131:1167-8.

7. Sakao T, Tsunooka N, Nakagawa H, et al. Ruptured saccular aneurysm of a coronary artery to pulmonary artery fistula associated with cardiac tamponade. Kyoubu Geka 2000;53:684-6. 